\title{
Para uma arte afirmativa, o exercício da liberdade: a problemática do espectador conforme Frederico Morais ${ }^{1}$
}

TAMARA SILVA CHAGAS

Resumo

O presente artigo trata de uma pesquisa teórica que visa delinear a emergência de um espectador atuante, elemento constituinte da obra, durante a pós-modernidade, e destacar a contribuição do crítico de arte Frederico Morais para tal debate. Usamos como referencial teórico textos do crítico citado, de Brian O'Doherty (2002) e de Herbert Marcuse (2005). Veremos que, para Morais, a experiência criativa do público, em contato com as propostas engajadas da arteguerrilha (em plena vigência do AI-5), poderia instigar o espectador a tomar um posicionamento diante da conjuntura política do país à época. Morais, em consonância com as reflexões de Herbert Marcuse, defendeu a imersão do público no ato criador como um exercício libertário capaz de retirar o espectador-sujeito de estruturas sociais excludentes.

Palavras-chave:

Frederico Morais, espectador, arte e política 


\section{For an affirmative art, the exercise of freedom: the problematic of the spectator according to Frederico Morais ${ }^{1}$}

TAMARA SILVA CHAGAS

Abstract

This article is a theoretical research that aims to trace the emergence of an active spectator as an element of the artwork during post-modernity and highlight the contribution of the Brazilian art critic Frederico Morais for this debate. We use as referential some texts written by Frederico Morais, Brian O'Doherty and Herbert Marcuse. We will see that, according to Morais, the creative experience of the public could instigate him to take a position on the Brazilian political situation. Morais, in line with Herbert Marcuse's texts, defends the public's immersion in the creative act as a libertarian exercise that can free the

Keywords: spectator of exclusionary social structures. 


\section{Por un arte afirmativo, el ejercicio de la libertad: La problemática del espectador segú Frederico Morais ${ }^{1}$}

\section{Resumen}

El presente artículo se centra en una investigación teórica que tiene el objetivo de esquematizar la manifestación de un espectador actuante, elemento constituyente de la obra, durante la posmodernidad, y destacar el aporte del crítico de arte brasileño Federico Morais para dicho debate. Como referencial teórico, utilizamos textos del mencionado crítico, de Brian O'Doherty (2002) y de Herbert Marcuse (2005). Percibiremos que, para Morais, la experiencia creativa del público, en contacto con las propuestas comprometidas del arte-guerrilla (en plena vigencia de la Dictadura Militar en Brasil - AI-5) podría instigar al espectador a posicionarse ante la coyuntura política del país en aquella la época. Morais, en concordancia con las reflexiones de Herbert Marcuse, defendió la inmersión del público en el acto creador, como un ejercicio libertario capaz extraer al espectador-sujeto de estructuras sociales excluyentes.

Palabras clave:

Frederico Morais, espectador, arte y política 


\section{O espectador e o cubo branco}

A questão da urgência de um espectador-participante, experimentador e agenciador de situações, para a arte das décadas de 1960 e 1970, em detrimento da postura contemplativa do espectador tradicional, foi uma problemática manifesta nas reflexões do crítico de arte brasileiro Frederico Morais. Nascido em 1936, em Belo Horizonte, Minas Gerais, o crítico acrescentou às discussões da época considerações sobre a arte-guerrilha e sobre o processo de (des)alienação do espectador perante a experiência criativa, temáticas, certamente, fundamentais para a análise da situação do público nesse contexto.

A falência da crença na obra de arte como entidade autônoma e imbuída de forte caráter aurático (BENJAMIN, 1969) trouxe à tona a crescente necessidade de inclusão do espectador no âmago do trabalho de arte, ou melhor, de uma expansão da arte em direção ao espaço-tempo, "ser-aí" do espectador. Tal fato corresponde a uma tendência à descentralização da origem dos sentidos atribuídos a um trabalho artístico, não mais considerado como exclusivamente inerente à obra - perspectiva que legitimava seu fechamento em favor de um discurso privilegiado perante os demais possíveis: o da crítica tradicional, munida de um instrumental teórico específico e denso repertório visual.

O deslocamento do sentido da arte de si mesma para o "entre" oriundo das relações que a mesma mantém com seu contexto literal, social ou ideológico, e ainda, com o organizador/curador, o artista, o crítico e, sobretudo, com o público, promoveu sua abertura para que a mesma abarcasse uma multiplicidade de possíveis discursos interpretativos. A busca por um espectador-participativo, agente constituinte do tra- 
balho artístico, intensificou-se com a produção de inúmeras vertentes da arte dos 1960, do minimalismo à body art. Essa procura contrapunha-se ao que seria chamado, nos anos 1970, pelo artista e crítico Brian O'Doherty (2002, p. XIII), de "etiqueta do cubo branco"2: o comportamento padrão esperado do espectador no trato com a obra no ambiente institucional, sendo o Museu de Arte Moderna de Nova York a entidade promovedora dessa ideologia e o museu-modelo da mesma para as demais instituições museológicas modernas.

Nesse sentido, a postura tradicional exigida do espectador pelo museu moderno foi de contemplação e passividade. $\mathrm{O}$ olhar contemplativo sobrepujava os demais sentidos humanos, malquistos em um espaço onde o desejo por assepsia e perenidade destoava do aspecto caótico da vida citadina. Segundo O'Doherty (2002, p. XIII), o museu moderno qualifica-se como lugar atemporal e imaculado, apartado do mundo exterior, para conservar e expor a obra de arte - objeto de valor cultual.

De modo semelhante a essa perspectiva, Morais, ao falar das ações de Artur Barrio, como o depósito de detritos em espaços públicos, em artigo de abril de 1970, afirma que "O museu é uma espécie de templo - intocável e puro, mantendo incólume a obra de arte, mesmo se esta for um montulho de lixo [...]" (MORAIS, 1970a, n. p.). Para entrar em tal espaço, conforme O'Doherty, é exigida uma conduta específica do espectador: colocar-se diante de uma obra aurática assemelha-se a um ritual religioso. Quanto a isso, vale citar:

A obra é isolada de tudo que possa prejudicar sua apreciação de si mesma. Isso dá ao recinto uma presença característica de outros espaços onde as convenções são preservadas pela repetição de um sistema fechado de valores. Um pouco de Santidade da igreja, da formalidade do tribunal, da mística do laboratório de experimentos junta-se a um projeto chique para produzir uma câmara de estética única. Dentro desta câmara, os campos de força da percepção são tão fortes que, ao deixá-la, a arte pode mergulhar na secularidade. (O'DOHERTY, 2002, p. 3)

O automatismo da postura requerida desse espectador tradicional abordado por O'Doherty pode ser identificado com a passividade do indivíduo e das massas diante de estruturas sociais excludentes, tal como sugere o artista argentino Julio Le Parc, no texto “Guerrilha Cultural?”, de 1968, quando escreve que "as determinações unilaterais no campo artístico 
são idênticas às determinações unilaterais no campo social" (LE PARC, 2006, p. 201)3. O autoritarismo e o elitismo no âmbito da arte, para Le Parc, geram códigos absolutos e inacessíveis ao espectador não especialista em arte.

A arte convencional, posta em xeque pelo artista argentino, a qual pode ser associada ao contexto da ideologia do cubo branco, destina-se a uma casta diminuta e cria um discurso para justificar a exclusão dos que não pertencem a essa elite. Todavia, a postura adotada por Frederico Morais com relação ao museu aparenta ser, a princípio, contraditória. Por um lado, em carta endereçada ao artista Luciano Gusmão, de fevereiro de 1970, o crítico afirma que:

[...] hoje só tem vitalidade a arte que está inteiramente do lado de fora [...] dos museus, galerias, de todo e qualquer local sagrado e irrecuperável, que não pode ser vendida ou colecionada. Melhor que o 'Palácio das Artes' é o Parque Municipal, em torno. Melhor que a sala de exposições da Reitoria é aquele vazio de terra, em derredor. Melhor que o Museu da Pampulha é a montanha que está próxima. (MUSEU DE ARTE DA PAMPULHA, 2008, p. 26)

Por outro lado, no manifesto "Do Corpo à Terra", distribuído em abril de 1970 no contexto do evento homônimo, que contou com trabalhos de artistas conceituais e engajados, Morais defende que o museu se torne invisível "pelo excesso de sua presença” (MUSEU DE ARTE DA PAMPULHA, 2008, p. 46-47) e seja o "plano-piloto da futura cidade lúdica" (MORAIS, 1970a, n. p.). Ele qualifica, ainda, a sala de exposições do Palácio das Artes, bem como o Parque Municipal de Belo Horizonte, onde ele se encontra, como "áreas de liberdade" (MUSEU DE ARTE DA PAMPULHA, 2008, p. 26).

A questão para Morais passa, na verdade, por sua compreensão do "museu de arte pós-moderna" (MORAIS, 1975, p. 58) como um centro gerenciador de atividades ligadas à criação, realizadas no âmbito da cidade, vista como sua extensão ${ }^{4}$. Nesse sentido, o museu ultrapassa as paredes do prédio onde ele está instalado: seu sentido como local expositivo e de conservação de acervo. Morais (1975), dessa forma, não supõe sua falência, mas, ao contrário, propõe transformar sua função, adaptando-o às demandas do mundo contemporâneo e integrando-o plenamente à vida da cidade.

Conforme Le Parc (2006), o sistema artístico reproduz a estrutura sociopolítica capitalista, calcada na relação dualista 
entre dominantes e dominados e, assim, corrobora para sua manutenção. Contrapondo-se a tal fato, Le Parc (FERREIRA; COTRIM, 2006, p. 202) propõe o combate às normativas estabelecidas no âmbito artístico e social por meio daquilo que denominou de guerrilha cultural, que abarcaria ações engajadas dos artistas a fim de denunciar e confrontar o sistema estabelecido, noção essa muito semelhante à de "guerrilha-artística" (MORAIS, 1975, p. 26), comentada por Frederico Morais, e vinculada às discussões acerca da "Nova Crítica" e da arte de vanguarda dos anos 1960 e 1970, apoiada pelo referido crítico.

\section{A arte como experiência libertária}

A constatação da mudança da noção mais ortodoxa de obra e a abertura da arte para um diálogo com o contexto e com o espectador foram temáticas recorrentes na atuação crítica, artística e curatorial de Frederico Morais no âmbito da arte brasileira das décadas de 1960 e 1970. Se a obra, por um lado, tornou-se - por meio das ações dos artistas das vanguardas -, situação, experimentação e processo, o espectador, por outro, transformou-se em agente ativo constituinte dela.

De acordo com o escrito por Morais (197ob, p. 50-51), o artista, nesse ínterim, é apenas o propositor, aquele quem, nas palavras do crítico, "puxa o gatilho" de uma ação/acontecimento sem roteiro pré-definido, ação essa cujos desdobramentos dependem da participação efetiva do público. As propostas plurissensoriais, comprometidas com a ativação da consciência do próprio corpo pelo público e com a vivência da arte como atividade lúdica, tão comuns na arte brasileira durante os anos 1960, fundamentavam-se na procura por esse novo espectador. Lygia Clark e Hélio Oiticica são alguns dos artistas que se dedicaram à aproximação da arte à ludicidade e elaboraram propostas vivenciais envolvendo a ativação de seus sentidos.

Não obstante, para Morais, a questão do espectador-participante seria radicalizada apenas com o advento da denominada "arte-guerrilha" (ou guerrilha artística, ou ainda, "contra-arte" 5$)^{6}$, conceito que faz alusão às ações das guerrilhas rurais e urbanas no Brasil e em outros países periféricos à época, sob a regência de regimes ditatoriais. Apropriando-se do conceito elaborado por Décio Pignatari (1973) e expandindo as reflexões acerca dele - além de estar em consonância com as conjecturas do já citado Julio Le Parc -, Morais argumenta em favor de uma arte de confronto, participativa e capaz de 
desestruturar as convenções artísticas mais conservadoras; capaz, ainda, de ativar corpo e mente do espectador para a realidade que o cerca, por meio da criação.

Morais (1975) defende que o artista-guerrilheiro é responsável por criar situações calcadas no imprevisto e no uso de estratégias e de materiais inusitados, os quais geram no espectador sentimentos como temor e repulsa, de forma a criar um estado de expectativa constante. Desse modo, exigiria dele a tomada de iniciativas. A arte-guerrilha seria, portanto, uma tentativa de relacionar as propostas da dita "geração tranca-ruas" (MORAIS, 1975, p. 26), engajada politicamente e conceitual às ações dos guerrilheiros. Segundo Morais (1975), a arte tradicional, nessa analogia, assemelha-se a uma guerra convencional, na qual elementos como o crítico, o artista e o público possuem funções fixas pré-delimitadas.

Contudo, na guerrilha artística, os papéis exercidos por cada um desses elementos são continuamente transformados: os limites entre essas castas se diluem. Não havendo mais a rígida separação de outrora entre crítico, artista, público, conservador e mercado, abre-se caminho para o intercâmbio desses papéis7. Nesse sentido, Morais (1975) fundamenta, além da sua própria atuação como crítico-artista - criador de trabalhos de arte que funcionam como comentário de outras proposições -, a tomada de iniciativa do espectador, cada vez mais intensa no referente à experiência artística (MORAIS, 1975, p. 26).

Diversamente da crítica tradicional, à qual ele se opunha e que se mostrava coerente com a estética europeia, analisadora dos aspectos compositivos da obra, a crítica criativa de Morais sugeria o experimentalismo em detrimento da ânsia pela objetividade, absoluta e excludente, validada pela própria História da Arte, ou melhor, por um discurso histórico oficial, de origem europeia. Conforme Morais, "a História da Arte lida com 'obras' (produtos acabados) ${ }^{8}$, que geram escolas ou ismos. Lida com estilos e tendências" (MORAIS, 1970b, p. 51). Não obstante, para o referido crítico há, também, coexistindo com essa história da arte oficial - impregnada de valores calcificados, elitistas e desatualizados -, uma "contra-história" (MORAIS, 1970, p. 51), a qual ele chama de "história guerrilheira" (MORAIS, 197ob, p. 51).

A contra-história se calca na tática do imprevisto, na sua recusa em se permitir cristalizar. Ela é formada por um conjunto de obras que permaneceram à margem da historiografia da arte oficial - e que possuem em comum o aspecto inacabado, mais próximo da ideia de projeto artístico que da noção 
de obra de arte - e culmina, enfim, na arte pós-moderna e na arte-guerrilha. Morais (1970b) argumenta que tal contra-história da arte se caracteriza por não possuir categorias e estilos. Ela, pensa-se, é território do híbrido e do múltiplo e, por isso, não pode se ater a critérios a priori.

Morais (1970b) prossegue, em seu texto, relacionando a contra-história com a questão do fim da arte, que foi ensaiado repetidas vezes por diversos movimentos da Arte Moderna, como futurismo e dadaísmo. Ele seria ainda mais uma vez evocado a partir das ações experimentalistas das vanguardas brasileiras dos anos 1960 e da geração conceitualista e engajada do final dessa década. Para Morais (197ob, p. 51), o enunciado "a arte acabou" não se relaciona ao término da produção criativa humana. Refere-se à própria dinâmica da arte: a da morte-vida, a qual se daria pelo movimento pendular das correntes artísticas que reiteram a arte e daquelas que a renegam ao fazer antiarte - proclamando seu fim temporário.

Décio Pignatari (1973), em seu já citado ensaio, assim como Morais, destaca a não linearidade das guerrilhas e o seu constante reinventar-se como características intrínsecas a elas. Suas estratégias contra a rigidez das estruturas hierarquizadas seriam o imprevisto e o sincronismo de suas ações, uma vez que "Na guerrilha, tudo é vanguarda e todos os guerrilheiros são vanguardeiros” (PIGNATARI, 1973, p. 159). Pignatari (1973) ainda defende o caráter estrutural das guerrilhas, pois as relações entre elementos são nelas realçadas, em contraposição à visão de eventos ou obras, na qual o elemento é vislumbrado apartado de seu contexto.

Um exemplo de situação de arte-guerrilha seria a proposição de Artur Barrio "Situação T/T1 (2 $2^{\mathrm{a}}$ parte)" (Figura 1) para a manifestação "Do Corpo à Terra", idealizada e organizada por Frederico Morais (Belo Horizonte, 1970). Barrio depositou suas trouxas ensanguentadas - realizadas com detritos, tecido, carne em decomposição, ossos e sangue - às margens do Ribeirão Arrudas, localizado na periferia de Belo Horizonte, onde eram frequentemente encontrados corpos de pessoas assassinadas. $\mathrm{O}$ teor polêmico de sua proposta, as consequências que ela trouxe para a vida quotidiana da cidade ao provocar a aglomeração de cerca de cinco mil pessoas no local e a presença do corpo de bombeiros e da polícia, tornam essa proposta emblemática para a discussão relativa à arte-guerrilha.

A estratégia de Artur Barrio de interferir diretamente no ambiente urbano por meio da arte permitiu a realização de sua proposição sem o seu impedimento pela censura, ferramenta 
de uso recorrente pelo Estado, principalmente no período de vigência do AI-5. A "situação artística" proposta por Barrio extrapolou os limites do convencionalismo na arte, tornando-se parte da vida quotidiana dos transeuntes da cidade, ao perder seu status de arte para se tornar puro acontecimento. Vale destacar que, ao falar sobre a obra de Barrio em artigo de jornal, Morais (1970c) critica a noção vigente de museu de arte como templo religioso, com a tendência de sacralizar tudo o que é inserido em seu contexto, inclusive lixo.

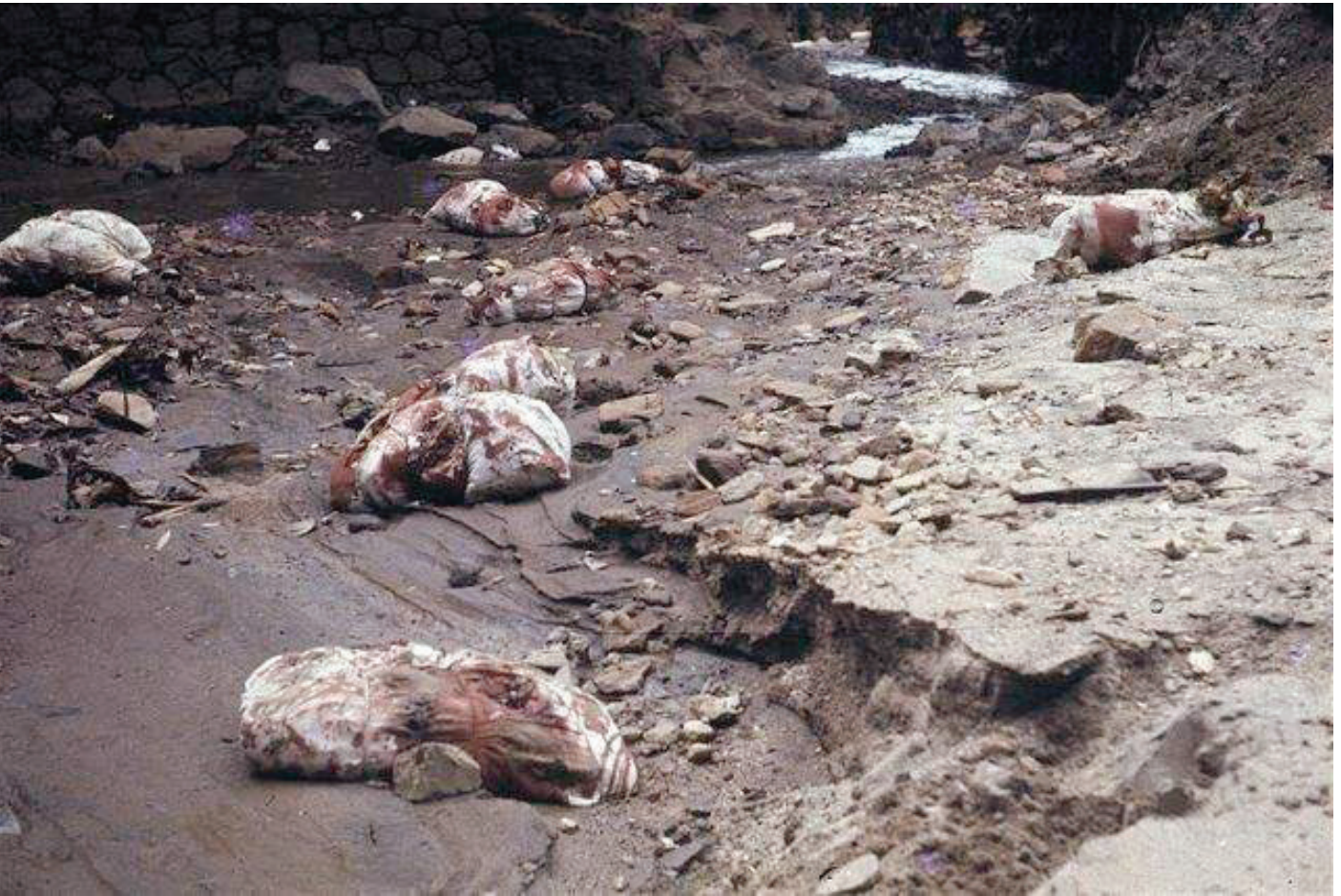

Figura 1 Situação $T / T_{1}$, de Artur Barrio, 1970

Fonte: <http://muvi.advant. com.br/artistas/a/artur_barrio/ sacosdecarne/e.jpg>, 2008. Acesso em: 02 nov. 2010.
Conquanto existam divergências em certos aspectos de seu pensamento em relação às considerações de Morais, o filósofo alemão Herbert Marcuse ${ }^{9}$ também salienta o potencial radical e libertário da arte imaginativa. Tal arte, ligada à rebeldia da juventude e opondo-se ao caráter obsoleto da arte tradicional, seria, conforme Marcuse (2005), capaz de transformar, por intermédio do não conformismo e do protesto, a sociedade afluente.

Segundo Marcuse (2005), a arte, ao distanciar-se de uma pretensa neutralidade diante da realidade social, qualifica-se, 
em primeiro lugar, como recusa do modelo de sociedade estabelecido. Em segundo, como afirmação da promessa de uma nova realidade e de um novo Homem, fundamentados na dimensão estética e criados a partir da destruição das antigas estruturas. Embora Marcuse explicite o caráter político da arte e seu papel na construção de uma sociedade livre, ele refuta a ideia de uma "arte política" (ou seja, panfletária). Quanto a isso, vale frisar que a relação entre arte e política para Frederico Morais também se contrapõe à redução da arte ao panfleto. Para o crítico, a aproximação entre arte e política se dá na medida em que a arte se confunde com o âmbito da vida e retira o comportamento do espectador de seu automatismo por meio da criação libertadora.

Morais (1972) cita os questionamentos lançados pelo crítico francês Michel Ragon, presentes no ensaio "O artista e a sociedade" (1968), que se indagava: como após os "happenings" (MORAIS, 1972, p. 7) das massas, durante o "Maio de 1968", "ousarão fazer ainda happenings de câmara" (MORAIS, 1972, p. 7)? Nesse sentido, as manifestações populares do "Maio de 1968" foram efetivamente tão radicais e criativas que parecem ter aproximado a arte ao quotidiano das massas. As manifestações estudantis ocorridas nas universidades francesas no começo do ano citado, inicialmente em prol de mudanças educacionais, foram o estopim dos protestos. Rapidamente os operários se somaram a eles, que terminaram por assumir feições revolucionárias, em favor de transformações políticas, trabalhistas e comportamentais à época do governo conservador do General Charles de Gaulle.

Os protestos, que contaram com larga adesão de diversos segmentos da sociedade francesa, culminaram no confronto direto com a polícia e na greve geral. Nos muros da cidade, palavras de ordem foram escritas, tais como as que Morais destaca: "A arte está morta: criemos a nossa vida cotidiana" (MORAIS, 1972, p. 7) e "Plutôt la vie" (MORAIS, 1972, p. 7). Morais também ressalta as ideias do sociólogo Alfred Willener, que associa os eventos ocorridos com o advento de uma sociedade nova e criativa: "Maio de 68 seria, então, [...] o encontro de si mesmo na coletividade, a liberação de potencialidades individuais sob uma forma coletiva, sugerindo, portanto, um comportamento social e político novo, isto é, criativo" (MORAIS, 1972, p. 7). A massa, antes reles consumidora passiva, seja de arte, no caso de estudantes e intelectuais, seja de entretenimento, no caso das camadas mais apartadas do circuito da arte, passa a intervir criativamente na vida quotidiana. 
O artigo acima referido apresenta e relaciona tais questões levantadas por Ragon e Willener aos "Domingos da Criação", realizados no MAM-Rio, entre os meses de janeiro e junho de 1971, e de responsabilidade de Frederico Morais. Nessa série de seis eventos, realizados nos últimos domingos dos meses citados, o numeroso público participante - cerca de dez mil pessoas (MORAIS, 1995, p. 320) - foi convidado a tomar parte em atividades lúdico-criativas coordenadas por artistas. Cada um desses eventos foi dedicado ao uso de um material inusitado, de acordo com o princípio defendido por Morais e pelos artistas de vanguarda de que qualquer tipo de material pode ser transformado em arte. Seus títulos eram os seguintes: "Um domingo de papel", "O tecido do domingo", "O domingo por um fio", "Domingo terra a terra", "Corpo a corpo do domingo" e "O som do domingo". Segundo Morais (1995), procurava-se, com essas propostas, debater o conceito de domingo como contexto de um lazer repetitivo e alinhado a uma estrutura social alienadora, na qual o trabalho é improdutivo.

Nessa conjuntura asfixiante, não há lugar para a criatividade. Os "Domingos da Criação" surgem, logo, com o intuito de inserir o público participante dentro do próprio ato criador, de modo que ele não permaneça mais alienado em relação à criação e à arte (MORAIS, 1972). Morais (1972), nesse sentido, mobiliza e ativa o espectador ao retirá-lo de seu automatismo quotidiano, por meio da intervenção em seu tempo de lazer. Qualquer um poderia ser sujeito dessa transformação causada pela atividade criadora, não importando, para tanto, sua condição econômica, social ou cultural.

A proposta era aproximar a criação e a ludicidade da pessoa comum, o que, de fato, o projeto conseguiu, devido ao grande número de participantes dos mais diferentes estratos sociais, em virtude da larga divulgação pela imprensa. Entre os artistas integrantes, estão: Carlos Vergara, António Manuel, Lygia Pape, Ascânio MMM, Maurício Salgueiro, Ivan Serpa, Eduardo Ângelo, Paulo Herkenhoff e Wilma Martins, entre outros. Um dos detratores do projeto foi Walmir Ayala, que, em sua coluna no Jornal do Brasil, qualificou o evento como uma "bagunça" (SAMPAIO, 1971, p. 10). O crítico Márcio Sampaio, por outro lado, apoiou a ideia de Morais.

Vale acrescentar que os "Domingos" também surgiram como uma extensão das atividades educativas do MAM-Rio, instituição a qual Morais estava vinculado como diretor do setor de cursos. De acordo com o crítico (MORAIS, 2011), os eventos eram também uma forma de contestar o ensino tradicional das 
artes, permeado pela relação hierárquica professor-aluno. Para além do caráter evidentemente lúdico dos "Domingos", a pesquisadora Dária Jaremtchuk (2005) percebe-os como um fenômeno político, pois os mesmos transformaram o MAM-Rio em um espaço de resistência ao circuito artístico oficial, este último afinado à lógica do mercado e ao governo ditatorial da época.

Os "Domingos" também problematizaram o espaço museológico, tornando-o democrático, aberto à participação do espectador, e expandiram seu local de ação para o lado de fora, a saber, o próprio Aterro do Flamengo, inserindo-se na vida quotidiana das pessoas comuns. Nesse sentido, o MAM-Rio se transformou naquilo que Morais preconizou a respeito do museu de arte pós-moderna: um "organismo vivo" (MORAIS, 1975, p. 58) e um "laboratório para experiências" (MORAIS, 1975, p. 58), para além de local de conservação de obras-primas. Com os "Domingos", a distância entre artista e público se diluiu e o museu passou a se tornar um espaço de vivência da experiência estética por parte deste último, que abandona seu status de consumidor para tornar-se criador. Ou seja, de um elemento passivo, fragmentado e subjugado à lógica do mercado, o espectador se reinventa e se torna sujeito ativo do processo de criação, um homem "integral" (MORAIS, 1972, p. 7).

Vale comparar a ideia do espectador como criador àquelas de Roland Barthes (2004) presentes no ensaio "A morte do autor", de 1968. Para o filósofo, o autor é uma invenção moderna, que ganha uma relevância ainda maior com o positivismo, quando é colocado como uma figura de centralidade inquestionável (não apenas no contexto literário, mas também cultural), superior à linguagem da obra, relegada a segundo plano. Quando morre o autor - outrora visto como detentor das chaves para a decifração do texto -, no século XX, vem à tona o leitor, cuja impessoalidade permite ao texto seu caráter ambíguo, isto é: a multiplicidade de escritas (ou a "écriture", conforme registra o filósofo em outros ensaios) que ele, texto, de fato, é.

Também nas manifestações criativas das massas durante o Maio de 1968, da qual falam Ragon, nesse mesmo ano, Willener, em 1970, e Morais, em 1975, a autoria se dilui. Acredita-se que as frases escritas nos muros e as outras manifestações populares não pertencem a um autor, a uma origem da qual se possa inquirir algum sentido a ser decifrado ou a uma voz específica que, por meio da repressão, possa se fazer calar. Pelo contrário, tais frases são polifônicas e visam ao leitor anônimo, que pode simplesmente manter-se como tal, ou, incitado pelas ações do coletivo, repetir, por sua vez, esse gesto criador. 
Nesse contexto, o público, como corpo coletivo, possui significativo poder transformador na política e na esfera da arte, e age tal como artista. O coletivo, reforçado através do anonimato das ações, ao contrário de subtrair o dado subjetivo do ato, intensifica a experiência do sujeito de si mesmo (MORAIS, 1975).

O público como agente na arte é, portanto, também agente político: ele, desperto para a criação, interfere em sua realidade, modificando-a. O espectador assume-se, por meio da experiência artística, como ser atuante no mundo. Dessa forma, ele se situa, no pensamento do crítico Frederico Morais, como elemento ativo constituinte do trabalho artístico. Ele é agente transformador do significado de uma proposta que, sendo o artista apenas seu propositor - e não detendo o controle dos desdobramentos da situação que inicia -, necessita do público para existir.

Tais contribuições de Frederico Morais foram fundamentais para o contexto da arte brasileira nos anos 1960 e 1970. Tanto mediante sua atividade como organizador de manifestações artísticas (Domingos da Criação, Arte no Aterro, Do Corpo à Terra) e participação em júri de salões (Salão da Bússola, IV Salão de Arte Moderna de Brasília), quanto nas suas atuações como crítico-escritor e como crítico-artista, as questões da "arte-guerrilha" e da real inclusão do espectador no ato criativo são visíveis nas reflexões de Morais da época e referenciais para a compreensão da atuação dos artistas experimentalistas dos anos 1960 e da geração da arte-guerrilha na conjuntura da arte brasileira.

NOTAS

1 Versão revisada e ampliada de texto publicado originalmente nos anais do V Simpósio Nacional de História Cultural, ocorrido em Brasília. Trecho também incluso na dissertação "Da crítica à Nova Crítica: as múltiplas incursões do crítico-criador Frederico Morais", com orientação da Professora Dra. Almerinda da Silva Lopes e defendida em 2012. Bolsa: CAPES (2010-2012)

2 Vale ressaltar que alguns autores contestam a aplicação da teoria do cubo branco no contexto brasileiro, posto que muitos dos museus locais são modernistas e os mesmos se tratam de "caixas de vidro", em detrimento da noção de cubo branco. Nesse sentido, tais museus permitem a emergência da relação dentro versus fora do espaço museológico, em diálogo com a paisagem que os circunda. De fato, isso ocorre em alguns casos. Um exemplo a ser citado é o Museu de Arte Moderna do Rio de Janeiro e sua relação seu entorno, o Parque do Aterro do Flamengo. No entanto, apesar dessa vocação para o diálogo com o seu exterior, muitas dessas instituições ainda reverberam aspectos ideológicos em consonância com a teoria do cubo branco.

3 Também Paulo de Oliveira Reis, ao falar das exposições de arte realizadas no Brasil, nos anos 196o, traz ao debate a questão levantada por Le Parc. 
Para ler mais sobre isso, sugere-se o estudo da relevante tese do pesquisador. Cf. Reis (2005).

4 Segundo Frederico Morais, o termo "arte pós-moderna" foi utilizado pela primeira vez por Mário Pedrosa em debate realizado em ocasião do Salão da Bússola, em 1969, para definir o "novo estado de arte sem arte", contexto ao qual pertenciam os trabalhos experimentalistas inscritos no salão. Deve-se salientar, todavia, que já no artigo "Arte ambiental, arte pós-moderna, Hélio Oiticica", publicado no jornal “Correio da Manhã”, em 1966, Pedrosa (2004, p. 355) faz uso desse termo para se referir ao "novo ciclo de vocação antiarte", surgido a partir da Pop Art, e cita, como exemplos de artistas precursores desse novo contexto, Lygia Clark e Hélio Oiticica. Como indica seu título, o artigo é dedicado à poética ambiental desse último artista. Morais passa a fazer uso dessa expressão, conforme ocorre no quinto parágrafo do "Manifesto do Corpo à Terra", de 1970, em que fala sobre as transformações ocorridas na arte: "Da arte à antiarte, do moderno ao pós-moderno, da arte de vanguarda à contra-arte (proposições) a abertura é sempre maior" (MUSEU DE ARTE DA PAMPULHA, 2008, p. 47). Em texto publicado em 1975, Morais escreve: "Vê-se, pois, que estamos vivendo a 'arte pós-moderna' [...]”. O termo aparece, ainda, em outro artigo importante de 1970, a saber: "Contra a Arte afluente: o corpo é o motor da obra”. Todavia, vale salientar que seu uso é, ainda hoje, controverso, e seu sentido, variável. Anne Cauquelin, por exemplo, define o pós-moderno como o "atual", marcado pela heterogeneidade e que mescla o presente à referência à tradição histórica da arte, sem o imperativo da filiação a uma tendência. Outro ponto a se ressaltar é que Morais, mesmo por um lado, adotando o termo "pós-moderno" e defendendo uma arte pluralista, por outro, recupera e revigora, ao trazer para o contexto artístico de sua época, questões próprias da modernidade e que, teoricamente, não movem a pós-modernidade, tais como a vanguarda, a ruptura com a tradição e a utopia da arte como parte integrante do projeto de uma sociedade futura. Nesse sentido, ele parece estabelecer um diálogo simultâneo com o moderno e o pós-moderno. Cf. PEDROSA, Mário. Arte Ambiental, arte pós-moderna, Hélio Oiticica. In: ARANTES, Otília (Org.). Mário Pedrosa: acadêmicos e modernos. São Paulo: Edusp, 2004. p. 355-36o; MUSEU DE ARTE DA PAMPULHA, 2008, p. 47; MORAIS, 197ob, p. 51; CAUQUELIN, 2005, p. 127-133.

5 O termo "contra-arte" foi cunhado por Morais em texto de 1969, com o intuito de discernir as novas ações efếmeras e desmaterializadas - propostas por esses jovens artistas -, da antiarte, visto que elas, constata o crítico, lançam-se para além desta última, já institucionalizada. Vale também esclarecer que, de acordo com Morais, a arte-guerrilha é "o conjunto dessas manifestações" de contra-arte. (MORAIS, 197od, n. p.).

6 Para saber mais sobre tal tema, sugere-se a leitura da importante tese de doutorado do pesquisador Artur Freitas. Cf. FREITAS, 2007.

7 Vale notar que Frederico Morais associa a crítica tradicional àquilo que ele chama de "guerra convencional da arte", ou seja, um estágio anterior ao da arte-guerrilha, no qual artista, crítico e público formavam estratos cujos papéis eram rigidamente fixados e não permutáveis. A crítica de arte, naquele contexto, "ditava normas de bom comportamento, dizendo que isto era bom e aquilo ruim, isto é válido, aquilo não, limitando áreas de atuação, defendendo categorias e gêneros artísticos, os chamados valores plásticos e os específicos". Id. Arte é organização: o museu é o artista. Suplemento Literário de Minas Gerais, Belo Horizonte, ํㅜ jul. 1972. Sem indicação de página.

8 Parênteses utilizados pelo próprio autor da citação, Frederico Morais.

9 Cabe ressaltar que, de modo diverso a Morais, Marcuse refuta o ruído ou a agressividade na arte. Para o filósofo, a arte deve ser silenciosa e provocar catarse. (MARCUSE, 2005). 


\section{Referências}

AGUILAR, Gonzalo. Frederico Morais, o crítico-criador. Disponível em: < http://www.cronopios.com.br/site/colunistas.asp?id=3279>. Acesso em: 29 jun. 2008.

AMARAL, Aracy. Arte para quê? São Paulo: Nobel, 1984.

BARTHES, Roland. A morte do autor. In: O rumor da língua. São Paulo: Martins Fontes, 2004. Disponível em: < http://www.artesplasticas.art.br/guignard/disciplinas/ critica_1/A_morte_do_autor_barthes.pdf >. Acesso em: 27 set. 2011.

BENJAMIN, Walter. A obra de arte no tempo de suas técnicas de reprodução. In: VELHO, Gilberto (Org.). Sociologia da arte. Rio de Janeiro: Zahar, 1969. v. 4, p. 15-47.

CANONGIA, Ligia. (Org.). Artur Barrio. Rio de Janeiro: Modo, 2002.

. O legado dos anos 6o e 7o. Rio de Janeiro: Jorge Zahar, 2005.

CAUQUELIN, Anne. Arte contemporânea. São Paulo, Martins Fontes: 2005.

CHAGAS, Tamara Silva. Da crítica à Nova Crítica: as múltiplas incursões do crítico-criador Frederico Morais. 2012. Dissertação (Mestrado em Artes) - Programa de Pós-Graduação em Artes, Universidade Federal do Espírito Santo, Vitória, 2012. Disponível em:< http://portais4.ufes.br/posgrad/ teses/tese_5967_Da\%2ocr\%C3\%ADtica\%20\%C3\%Ao\%20 Nova\%2oCr\%C3\%ADtica.pdf > . Acesso em: 21 jan. 2016.

FERREIRA, Glória (Org.). Crítica de arte no Brasil: temáticas contemporâneas. Rio de Janeiro: Funarte, 2006. Crítica e presentação. In: FERREIRA, Glória; PESSOA, Fernando (Org.). SEMINÁRIOS INTERNACIONAIS MUSEU VALE DO RIO DOCE: CRIAÇÃO E CRÍTICA, 4., 2009, Vila Velha. Criação e crítica. Vila Velha: Museu Vale do Rio Doce, 2009. p. 189-199.

FREITAS, Artur. Contra-arte: vanguarda, conceitualismo e arte de guerrilha - 1969-1973. 2007. Tese (Doutorado em História) - Setor de Ciências Humanas, Letras e Artes, Universidade Federal do Paraná, Curitiba, 2007. Disponível em: < http://www.dominiopublico.gov.br/pesquisa/ DetalheObraForm.do?select_action=\&co_obra $=153358>$. Acesso em: 3 jan. 2012.

.(Org.). Clement Greenberg e o debate crítico. Rio de Janeiro, Jorge Zahar, 1997.

. Escritos de artistas: anos 60/70. Rio de Janeiro: Jorge 
Zahar, 2006.

JAREMTCHUK, Dária. Espaços de resistência: MAM do Rio de Janeiro, MAC/USP e Pinacoteca do Estado de São Paulo. In: SEMINÁRIO VANGUARDA E MODERNIDADE NAS ARTES BRASILEIRAS, 2005, Campinas. Anais eletrônicos... Disponível em: < http://www.iar.unicamp.br/dap/vanguarda/artigos_pdf/daria_jaremtchuk.pdf >. Acesso em: 13 ago. 2011.

LE PARC, Julio. Guerrilha Cultural? In: FERREIRA, Glória; COTRIM, Cecília (Org.). Escritos de artistas: anos 6o/70. Rio de Janeiro: Jorge Zahar, 2006. p. 198-202.

MARCUSE, Herbert. A arte na sociedade unidimensional. In: LIMA, Luís da Costa. (Org.). Teoria da cultura de massa. 7. ed. São Paulo: Paz e Terra, 2005. p. 259-270.

MORAIS, Frederico. Arte no parque: Do Corpo à Terra. Diário da Tarde, Rio de Janeiro, 8 abr. 1970a. Artes plásticas: a crise da hora atual. Rio de Janeiro:

Paz e Terra, 1975. Artes plásticas na América Latina: do transe ao transitório. Rio de Janeiro: Civilização Brasileira, 1979.

Contra a arte afluente: o corpo é o motor da obra. $R e$ vista de Cultura Vozes, Rio de Janeiro, ano 64, v. 64, n. 1, p. 45-59, jan./fev. 1970b.

- Criatividade de maio e os Domingos da Criação. Suplemento Literário de Minas Gerais, Belo Horizonte, 1 jul. 1972. p.7.

. Cronologia das Artes Plásticas no Rio de Janeiro. Rio de Janeiro: Topbooks, 1995.

. Morreu Narciso, a arte está na rua. Diário da Tarde, Rio de Janeiro, 9 jan. 1970c.

. Revisão/69-2: a nova cartilha. Diário da Tarde, Rio de Janeiro, Sem indicação de página. 6 jan. 197od.

Seminário Reconfigurações do público: arte, pedagogia e participação. Rio de Janeiro, MAM-Rio, 2011. Debate. Disponível em: < http:// http://www.youtube.com/ watch?v=xDVl_t5EzD8>. Acesso em 20 abr. 2012.

MUSEU DE ARTE DA PAMPULHA, 2008, p. 47; MORAIS, 1970, p. 51; CAUQUELIN, 2005, p. 127-133.

MUSEU DE ARTE DA PAMPULHA, 2008, p. 26, catálogo da exposição Neovanguardas.

O'DOHERTY, Brian. No interior do cubo branco: a ideologia do espaço na arte. São Paulo: Martins Fontes, 2002.

PEDROSA, Mário. Arte Ambiental, arte pós-moderna, Hélio Oiticica. In: ARANTES, Otília (Org.). Mário Pedrosa: aca- 
dêmicos e modernos. São Paulo: Edusp, 2004. p. 355-36o.

PIGNATARI, Décio. Teoria da guerrilha artística. In:

Contracomunicação. 2. ed. São Paulo: Perspectiva, 1973. p. 157-166.

REIS, Paulo. Arte de vanguarda no Brasil. Rio de Janeiro: Jorge Zahar, 2006.

REIS, Paulo Roberto de Oliveira. Exposições de arte: vanguarda e política entre os anos 1965 e 1970. 2005. Tese (Doutorado em História) - Setor de Ciências Humanas, Letras e Artes, Universidade Federal do Paraná, Curitiba, 2005. Disponível em: < http://acervodigital.ufpr.br/bitstream/handle/1884/2397/tese.pdf;jsessionid $=9 \mathrm{C}_{1} \mathrm{CDE} 104 \mathrm{~A}_{3} \mathrm{EEoBF}_{77}$ F66B805DCFC 7 D9? sequence=1 >. Acesso em: 22 jun. 2007.

SAMPAIO, Márcio. Paiê, me leva no museu. Suplemento literário de Minas Gerais, Belo Horizonte, 8 maio 1971. p. 10.

SEFFRIN, Silvana. (Org.). Frederico Morais. Rio de Janeiro: FUNARTE, 2004.

Aceito em: 22/04/2016

Aprovado em: 16/10/2017

\section{TAMARA SILVA CHAGAS}

tamara.chagası@gmail.com

Pesquisadora independente em História da Arte, graduada em Bacharelado em Artes Plásticas pela Universidade Federal do Espírito Santo (2008) e mestra em Artes, na linha de pesquisa "Estudos em História e Crítica da Arte", pela mesma instituição (2012). 